\title{
Biochar from cookstoves reduces greenhouse gas emissions from smallholder farms in Africa
}

\section{Cecilia Sundberg, et al. [full author details at the end of the article]}

Received: 29 August 2018 / Accepted: 29 May 2020 / Published online: 21 June 2020

(C) The Author(s) 2020

\begin{abstract}
Biochar produced in cookstoves has the potential to contribute to negative carbon emissions through sequestration of biomass carbon while also providing other benefits for sustainable development, including provision of clean renewable energy and increased yields in tropical agriculture. The aim of the reported research was to estimate effects on food production, household energy access and life cycle climate impact from introduction of biochar-producing cookstoves on smallholder farms in Kenya. Participatory research on biochar production and use was undertaken with 150 Kenyan smallholder farming households. Gasifier cookstove functionality, fuel efficiency and emissions were measured, as well as biochar effects on agricultural yields after application to soil. Cookstoves provided benefits through reduced smoke, fuel wood savings and char production, but challenges were found related to labour for fuel preparation, lighting and refilling. On-farm trials with varying rates of biochar inputs, in combination with and without mineral fertilizers, have led to a sustained increase of maize yields following onetime application. The climate impact in a life cycle perspective was considerably lower for the system with cookstove production of biochar and use of biochar in agriculture than for current cooking practices. Climate benefits from biochar production and use are thus possible on smallholder farms in sub-Saharan Africa, through reduced use of biomass in cooking, reduced emissions of products of incomplete combustion and sequestration of stable biochar carbon in soils. Biochar-producing cookstoves can be implemented as a climate change mitigation method in rural sub-Saharan Africa. Successful implementation will require changes in cooking systems including fuel supply, as well as farming systems, which, in turn, requires an understanding of local socio-cultural conditions, including power relations and gender aspects.
\end{abstract}

Keywords Biochar-producing gasifierstove $\cdot$ Bioenergy $\cdot$ Greenhouse gas $\cdot$ Woodfuel $\cdot$ Life cycle assessment

Electronic supplementary material The online version of this article (https://doi.org/10.1007/s11027-02009920-7) contains supplementary material, which is available to authorized users. 


\section{Introduction}

In sub-Saharan Africa (SSA), high rates of deforestation (Leblois et al. 2017) and soil fertility degradation (Le et al. 2016) contribute profoundly to climate change and food insecurity. Most households in SSA use wood, charcoal and/or crop residues as cooking fuels (Bonjour et al. 2013), hanging on to traditional open combustion systems that have low energy efficiency and produce high emissions of health-affecting gases and fine particles (Jetter et al. 2012). There is a need for integrated technologies along the agriculture-energy nexus that increase efficiency of energy generation and agricultural inputs. Stoves that pyrolyse biomass to produce heat for cooking and biochar for soil fertility improvement could be such an opportunity (Njenga et al. 2016; Whitman et al. 2011).

Biochar is defined as biomass heated under oxygen-limited conditions to form stable carbon structures, and its application to soil has received attention for the double benefits to soil fertility and carbon sequestration. Unlike biomass harvest residues, the biochar is persistent to microbial mineralization in the soil. Addition of biochar therefore contributes to sequestration of carbon from the atmosphere into soil for a long period of time and can be considered a technique for negative carbon dioxide $\left(\mathrm{CO}_{2}\right)$ emissions (Minx et al. 2018). When added to soil, biochar has complex effects on soil chemistry, physics and biology (Biederman and Harpole 2013). In an African context, it has been shown that biochar can increase crop yields significantly (Jeffery et al. 2017), which is very promising for a continent where low productivity in agriculture is a major challenge. Biochar can be produced from locally available biomass. This is an opportunity as well as a risk, considering that biomass is a renewable but limited resource with various uses. Char-producing pyrolytic cookstoves could potentially produce biochar from local biomass resources already being used for cooking, thus reducing, rather than increasing, biomass demand (Njenga et al. 2016). Emissions from traditional open fires are known to emit health-affecting gases and particles, and improved cookstoves can reduce such emissions substantially (Thomas et al. 2015). However, adoption rates for improved cookstoves have often been low, due to their relatively high cost and a lack of consideration of local socio-technical aspects in cooking systems (Stanistreet et al. 2014). There are likewise mixed experiences of adoption of new management technologies in agriculture (Andersson and D'Souza 2014; Glover et al. 2016). The expected climate benefits need to be assessed in greenhouse gas balances considering the whole bioenergy-biochar system (Sparrevik et al. 2013). Thus, a multi-disciplinary research project was initiated to investigate specific conditions of implementation of biochar production and use in rural smallholder farms in three sites in Kenya while quantifying the effects of such implementation. Detailed accounts of results from cooking tests, household surveys and field experiments are under preparation or already published (Gitau et al. 2019; Kätterer et al. 2019; Njenga et al. 2016; Njenga et al. 2017). We provide here an overview of how the cooking and cultivation systems are affected by biochar introduction.

The aim was to estimate the effects on food production, household cooking energy access and life cycle climate impact, from introduction of biochar-producing cookstoves on smallholder farms in Kenya. Selected experimental results on fuel efficiency, emissions and biochar production capacity in biochar-producing cookstoves and effects of biochar use on crop yields are presented. The life cycle climate impacts of biochar production and use is then estimated. Finally, implications for up-scaling of biochar systems in an African context are discussed. 


\section{Methods}

\subsection{Study area and baseline}

Experiments were carried out in three sites in Kenya: in Embu County in central Kenya close to Mount Kenya, in Kwale County near the coast south of Mombasa and in Siaya County in the western part of the country close to Kisumu and Lake Victoria.

Precipitation is normally slightly lower in Embu (1200 mm) than in Siaya (about $1350 \mathrm{~mm}$ ) and lowest in Kwale (about $1050 \mathrm{~mm}$ with large variation within the county) (www. climatedata.eu). Annual rainfall is bimodal with long rains from March to August, short rains from September to December and a dry period in the beginning of the year. Crops are usually grown during two seasons per year in Embu and Siaya and one season in Kwale. Maize (Zea mays), coffee (Coffea arabica) and tea (Camellia sinensis) are major crops in Embu, whereas maize and groundnuts (Arachis hypogaea) are major crops in Siaya. Under local conditions, yields of maize, the main subsistence crop in Kenya, are generally around $1 \mathrm{Mg}$ per hectare (ha).

A baseline survey of socio-economic and farm characteristics of 50 households in each site was performed in 2014-2015 (manuscript under preparation by Mahmoud et al.). In each site, the average size of households was between 4 and 6 people and average farm size was 0.9 1.2 ha. More than $80 \%$ of household heads had farming as their main occupation.

\subsection{Biochar-producing cookstoves}

In a first set of cooking trials, the biochar production rate, fuel use efficiency and emissions of carbon monoxide $(\mathrm{CO}), \mathrm{CO}_{2}$ and fine particulate matter $\left(\mathrm{PM}_{2.5}\right)$ of a biochar-producing top-lit updraft (TLUD) gasifier cookstove made of steel (Fig. 1) were tested in five households in Embu when cooking a standard meal for a household of 5 people. Emissions were measured as concentrations in the room at $1.5 \mathrm{~m}$ height continuously during the cooking session (see Njenga et al. 2016 for details on methods). In a second stage, 20 households in Embu (including the 5 involved in the first trials) were equipped with the cookstove after being trained in its use. After 5 months and 27 months, the 20 households were interviewed regarding their perceptions of the cookstoves. In a third stage, 50 households at each of the three sites (Embu, Kwale, Siaya) were equipped with a new version of the TLUD cookstove, named GASTOV. They were asked to save the biochar they produced for use in participatory on-farm field experiments in the next planting season. After 2-3 months of use, these 50 households from each site were interviewed regarding their experiences of cookstove use. Results from one of the sites, Kwale, are reported here (detailed reporting of these results are presented by Gitau et al. 2019).

\subsection{Trial design and cultivation}

Both traditional researcher-managed as well as participatory field trials were initiated onfarm in fields in smallholder farms, in cooperation with the local owners. The researchermanaged trials were supervised by researchers and technicians who decided on crop varieties, time and mode of planting and of fertilizer application rate. The participatory trials were managed by the farmers themselves in relation to all farming practices and supervised by local technicians. 

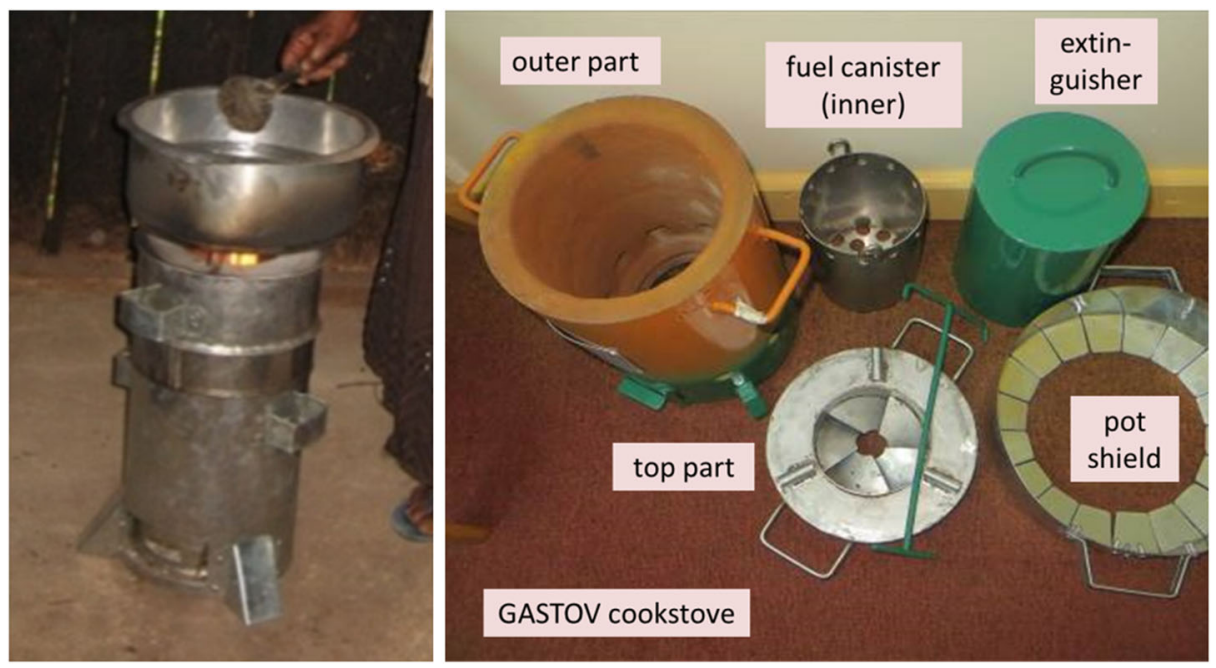

Fig. 1 Top-lit updraft (TLUD) gasifier cookstove used for combined cooking and char production. Left: the first version of the cookstove used in stages 1 and 2, which was made of steel sheets. Right: the second version of the cookstove (GASTOV) used in stage 3, which was slightly smaller and made of ceramics and steel

Data from two different field experimental series are described here. The first is a series of longterm researcher-managed field trials established in 2006, with complete data from trials established on one farm in Embu and on two farms in Siaya. A split-plot design with three replicates was used where unfertilized and mineral fertilized treatments (nitrogen, phosphorous and potassium (NPK) applied at locally recommended rates of $50-60 \mathrm{~kg} \mathrm{ha}^{-1}$ ) were main plot factors and biochar application occurred in subplots randomized within main plots. In these experiments, a total of $100 \mathrm{Mg}$ biochar ha ${ }^{-1}$ were applied to the topsoil $(0-20 \mathrm{~cm})$ in two equal doses in the first two seasons. The biochar used was made from Acacia $s p$. in traditional earth mound kilns. A crop rotation of maize and soybean (Glycine max) was established. Data from the first 20 seasons have been analysed, and a detailed account of this has been published by Kätterer et al. (2019).

As $100 \mathrm{Mg}$ biochar ha $^{-1}$ is a far too high biochar dose for use in practice, pot trials and field trials were set up to test the effect of lower doses (1-10 Mg biochar ha $\left.{ }^{-1}\right)$ with maize cultivation for 2-4 seasons. The results from these trials are in preparation and are not reported here.

Finally, about 50 farmers in each of Kwale and Embu used the biochar they had produced in the cookstoves. On each farm, two plots were set up (10 $\mathrm{m}^{2}$ in Embu and $20 \mathrm{~m}^{2}$ in Kwale), where one plot received biochar, and the other plot received no biochar. There were no other differences in management of the crops on these plots. Depending on the amounts of biochar produced on farm, application rates varied from 1 to $10 \mathrm{Mg} \mathrm{ha}^{-1}$. Biochar was spread evenly in the furrows and covered with soil before planting seeds (maize) or seedlings (kale). Kale (Brassica oleracea) was grown in Embu in the short rainy season of 2017, and maize was grown in Kwale in the long rainy season of 2017. Application of fertilizer, weeding and pest management followed farmers' local practice.

\subsection{Climate impact assessment}

Life cycle assessment (LCA) methodology was used to compare the climate impact of using a char-producing gasifier cookstove with current practices commonly found in rural areas, i.e. 
using the traditional three-stone open fire and the traditional charcoal stove (called Reference system). The net cooking energy need per household and year was used as a functional unit.

An overview of the life cycle stages and main processes is presented in Fig. 2. The life cycle started with biomass sourcing on farm, off farm and on the local market. The biomass used was mainly wood (including prunings from trees on farm), but in the gasifier systems, crop residues (maize cobs) were also used (see Table S1 for biomass mix in each system and Table S2 for biomass properties). The central process of the use phase was fuel combustion for cooking. In the two gasifier systems (called Charcoal and Biochar), char was harvested as a coproduct of heat for cooking. In the Charcoal system, all char was used for cooking, whereas in the Biochar system, all char was applied to soil. The long-term sequestration of biochar carbon in soil was included, but the complex effects of biochar on agricultural productivity and soil emissions were not considered.

In the Reference system, the farmers built the traditional earth mound kiln and the threestone stove by hand, using natural, unprocessed materials, so their construction and provision are not climate relevant. The production and end-of-life management of gasifier cookstoves was assumed to be minor and consequently omitted in the assessment.

For biomass supply, three alternative assumptions were made, either renewable (biomass carbon stock assumed constant), non-renewable biomass (woody biomass assumed not to be replaced by regrowth) or a mix of renewable and non-renewable feedstocks. Renewable and non-renewable represent two extremes of biomass use in a landscape with varying degrees of forest degradation. As a most likely scenario under current conditions, a mix of $43 \%$ nonrenewable biomass was assumed for off-farm sourcing in nearby forests and woodlands and $100 \%$ renewable biomass for on-farm wood and crop residues (Drigo et al. 2015).

\section{1) Reference: Current practices}

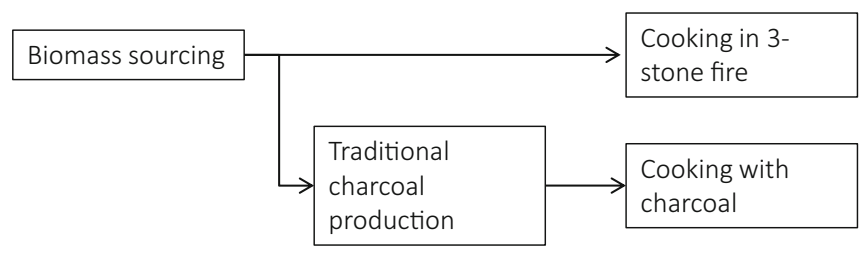

\section{2) Charcoal}

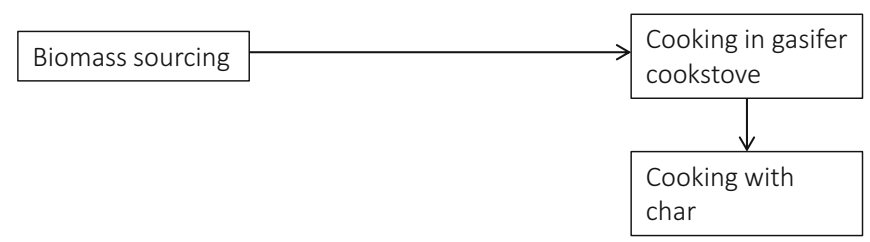

\section{3) Biochar}

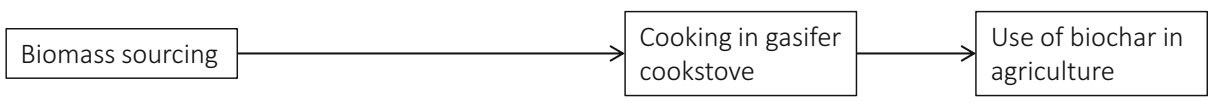

Fig. 2 Overview of the life cycle stages in each system analysed in the climate impact assessment. Current practices (system 1) were compared with cooking with the gasifier, with char from the gasifier used as a fuel for cooking (system 2) or as a soil amendment (system 3) 
Two sets of pollutants were considered; the well-mixed gases $\mathrm{CO}_{2}$, methane $\left(\mathrm{CH}_{4}\right)$ and nitrous oxide $\left(\mathrm{N}_{2} \mathrm{O}\right)$ are associated with low uncertainty (set 1$)$ and in set 2 also the ozone precursors $\mathrm{CO}$ and non-methane hydrocarbons, particulate matter (i.e., black carbon and organic carbon particles) and the aerosol precursor sulphur dioxide $\left(\mathrm{SO}_{2}\right)$ were included. These climate forcers involve considerably higher uncertainties because they are short-lived, not well-mixed and poorly understood in their effects on radiative forcing (Bailis et al. 2003; Grieshop et al. 2011). Emission data for the different processes are presented in Table S3.

Global Warming Potential over 100 years (GWP100) was used as a metric to quantify climate impact. GWP100 captures long-term impacts and is most suitable for comparisons with other studies due to its frequent use for well-mixed greenhouse gases. However, GWP100 leads to a misrepresentation of short-lived climate forcers included in set 2 (Grieshop et al. 2011; Fuglestvedt et al. 2003). Therefore, a 20-year time horizon is used for comparison, which is also in line with some previous studies in the field (Bailis et al. 2003; Smith et al. 2000a, b). Characterizations factors for the different pollutants are presented in Table S4.

\section{Results}

\subsection{Biochar-producing cookstoves}

Compared with traditional cooking, the first version of the gasifier domestic cooking system saved $20-43 \%$ of fuel depending on fuel type and calculation method and reduced cooking time by $18 \%$ when using the same woodfuel (Njenga et al. 2016). Kitchen concentrations of $\mathrm{CO}$ were reduced by $45 \%$ and $\mathrm{PM}_{2.5}$ by $89 \%$.

In Kwale, $98 \%$ of the households used firewood for cooking, but only $2 \%$ used firewood exclusively. About three quarters of households combined firewood with crop residues. Charcoal was used by $42 \%$ of the households, which they either purchased, produced in kilns on-farm, collected from friends' farms or collected from the three stone open fire. Less than $20 \%$ of households also used paraffin or liquid petroleum gas (LPG) for cooking. A variety of firewood types were used, including fruit tree prunings as a major category. Firewood sources included on-farm (96\% of households), local market (26\%), friends' farms (22\%), natural forest $(6 \%)$, a private plantation $(6 \%)$ and community land $(4 \%)$. On farm was the only source of firewood for $41 \%$ of the households.

The survey of user perceptions of cookstoves in Kwale and Embu showed that the cookstove was appreciated by the users because it saved fuel, produced less smoke and produced charcoal. Users in Embu appreciated also that it warmed the house, saved time and cooked faster for meals that cooked quickly and hence did not require refilling of fuel. In Kwale, the gasifier was reported to be easier to clean, easier to adjust heat, easier to handle, with less human exposure to heat and better at maintaining cleanliness of pot and kitchen, when compared with the three-stone open fire. Other benefits of the gasifier were lack of need to push wood and blow fire.

The challenges experienced in the use of the gasifier were mainly labour-related, to the cutting and packing of small $(20 \mathrm{~cm})$ pieces of fuel wood in the canister, to more timeconsuming lighting of the stove, to refilling when fuel finished before the food was ready and to harvesting of the charcoal. Many users pointed out that the gasifier could not be used to cook large amounts of food and food that takes a long time to cook as that required refilling with fuelwood. 


\subsection{Cultivation}

In the 20 season long-term field experiments, which were described in detail by Kätterer et al. (2019), biochar addition in general improved soil functions through increased soil porosity, $\mathrm{pH}$, plant-available $\mathrm{P}$ and soil water holding capacity. Crop yields responded positively to both biochar and fertilizer at all sites and yield increases attributable to biochar were similar both in presence or absence of mineral fertilizers, so the effects of biochar and mineral fertilizer were additive (ibid). Interestingly, treatments that had received biochar applications managed to sustain production even in a very dry season. Coefficients of variation in crop yield between seasons in treatments receiving biochar were reduced by $50 \%$ for maize and $29 \%$ for soybean compared with the treatments receiving no biochar (ibid). Biochar-amended soils could store in average $5 \mathrm{~mm}$ more water than unamended soils, highlighting the water holding capacity and potential of biochar as a drought resistant agricultural production option. Yield increases due to biochar application were about $1.17 \mathrm{Mg} \mathrm{ha}^{-1}$ (corresponding to $84 \%$ of the yield in the unfertilized control) for maize and $0.43 \mathrm{Mg} \mathrm{ha}^{-1}$ (64\% of the yield in the control) for soybean independent on fertilization on average over seasons and sites. The effect of biochar was persistent over time. At one of the sites, yields even increased significantly with time in the fertilized treatment, indicating a positive feedback on soil fertility.

In the experiments where farmers used the biochar they themselves had produced (Table 1), many plots were discontinued due to a drought, but 20 of the farms in Kwale continued the trials until the planned harvest time. In all those farms, there was a significant maize grain yield response to biochar (Fig. 3). Yields ranged from $0.9 \mathrm{Mg} \mathrm{ha}^{-1}$ in the control plots to $4.4 \mathrm{Mg}$ in the biochar plots, on average in the first season. Biochar application rate positively affected the maize yield increases, and this response was not dependent on whether fertilizer was applied or not at the individual farms. In Embu, only 25 farms continued the trials until the planned harvest time due to a drought. The average increase in kale yields with biochar addition was $33 \%$, and a yield increase was observed in $68 \%$ of the farms.

\subsection{Climate}

The climate impact assessment showed that under all circumstances, cooking with the gasifier and using biochar as a soil amendment were the best options from a climate perspective when compared with current practices or using char as a fuel. Depending on pollutant set, time frame

Table 1 Characteristics of biomass used and biochar produced from Gastov cookstoves in 5 households in Embu, average and standard deviation

\begin{tabular}{llll}
\hline Characteristic & Unit & Biomass & Biochar \\
\hline Biomass type & & $\begin{array}{l}\text { Prunings from 5 wood types: } \\
\text { Coffee, Grevellia, Macadamia, Mucuca, Muriru }\end{array}$ & $8.7 \pm 0.3$ \\
$\mathrm{pH}$ & - & $3.3 \pm 0.7$ \\
Ash & \% of dry matter (DM) & $0.9 \pm 0.4$ & $9.7 \pm 0.6$ \\
Volatile matter & \% of DM & $81.9 \pm 1.1$ & $87.0 \pm 0.8$ \\
Fixed carbon & \% of DM & $17.1 \pm 0.7$ & $1.7 \pm 0.2$ \\
Hydrogen & \% of DM & $6.0 \pm 0.1$ & $33.7 \pm 0.1$ \\
Net calorific value & $\mathrm{MJ} \mathrm{kg}^{-1} \mathrm{DM}$ & $18.5 \pm 0.2$ & \\
\hline
\end{tabular}




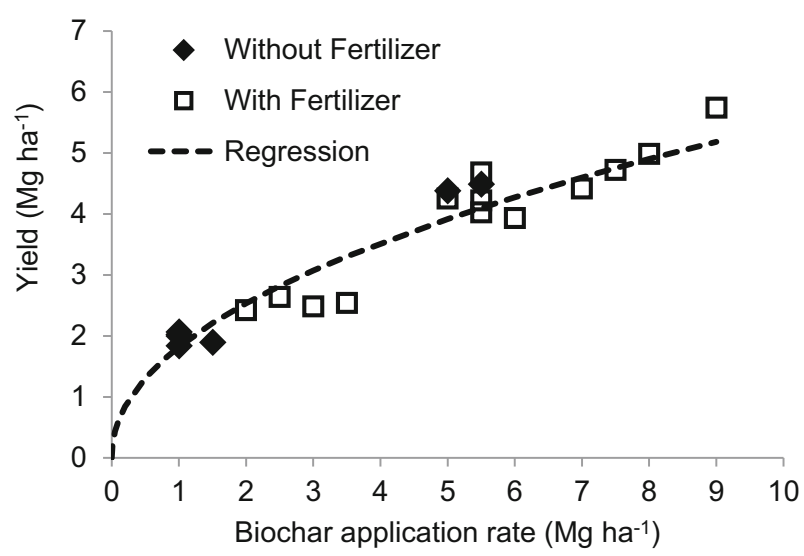

Fig. 3 Yield increase (yields with biochar application minus yields in control plots with same management but without biochar) as a function of biochar application rate, for farmer-managed maize trials in Kwale, with or without fertilizer. The data presented are from the first season, when biochar was applied just before planting. The yield response could be well described by the regression equation $y=1.82 \times 0.476 ; R^{2}=0.91$

and assumptions regarding biomass regrowth, the climate impact reduction compared with the Reference ranged from 54 to $100 \%$ plus net carbon sequestration of $84 \%$ of the original emission (Fig. 4).

Benefits arose from fuel efficiency, cleaner combustion and carbon sequestration in soil (Fig. 5). When GWP100 and the limited set of pollutants were used, the Gasifier + biochar system had a small net negative climate emission at default assumptions of deforestation. With GWP20 and the larger set of pollutants, soil carbon sequestration did not fully compensate for emissions from combustion, so the net climate impact was still positive. Cooking with the gasifier and using char as a fuel was the second best option under all assumptions due to fuel efficiency and reduced air emissions compared with current practices. The difference in GWP between using char as a soil amendment or as a fuel was smaller when non-renewable biomass was used as feedstock (Fig. 4).

\section{t $\mathrm{CO}_{2}$ e per household per year}

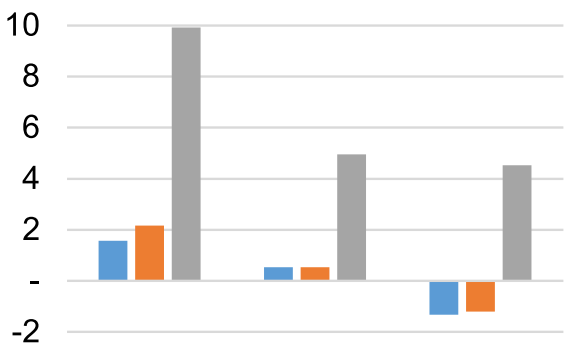

Reference Charcoal Biochar

\section{t $\mathrm{CO}_{2}$ e per household per year}

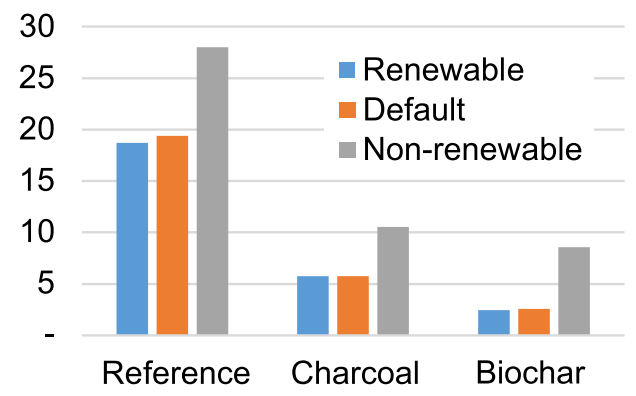

Fig. 4 Climate impact of the three systems (Reference, Charcoal and Biochar) assessed with pollutant set 1 and GWP100 (left) and with set 2 and GWP20 (right), expressed as tonnes (t) $\mathrm{CO}_{2}$ equivalents from cooking per household per year. Three alternative assumptions for biomass were used: fully renewable (blue); renewable except off-farm wood, which is $43 \%$ non-renewable (default, orange); and all woody biomass is non-renewable (grey) 


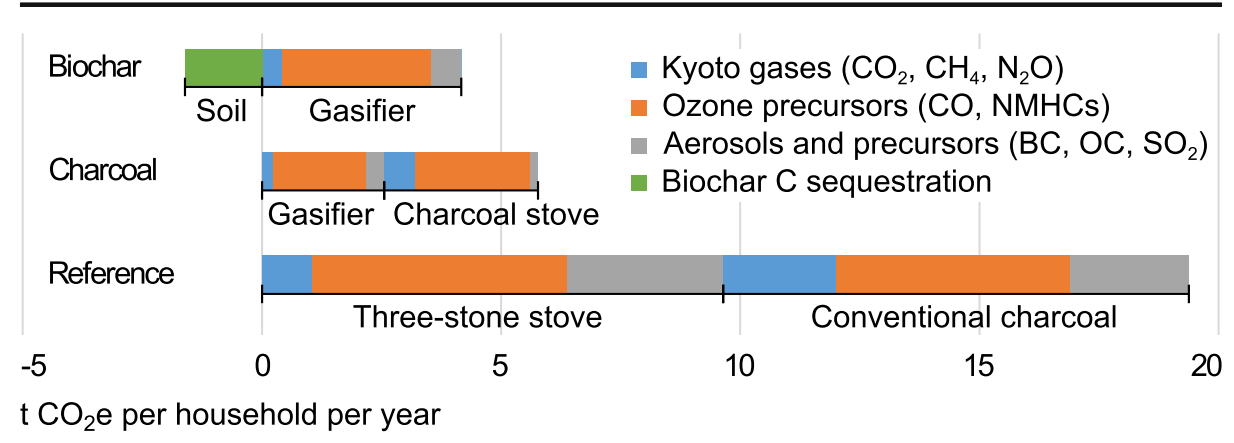

Fig. 5 Contribution of the different processes and climate forcers to the climate impact in the Reference, Charcoal and Biochar systems, using pollutant set 2 and GWP20. Climate impacts are expressed as tonnes (t) $\mathrm{CO}_{2}$ equivalents from cooking per household per year

\section{Discussion}

\subsection{Direct and indirect climate impacts}

As quantified in the climate impact assessment, biochar from cookstoves has potential to contribute to climate change mitigation as a negative emission technology, reducing the $\mathrm{CO}_{2}$ concentration in the atmosphere, and also by reducing emission of other greenhouse gases. First, this is through sequestration of carbon in the biochar as such, which was quantified as a negative emission (Fig. 5). Biochar addition to soil also has other indirect effects on climate, e.g. related to crop productivity, where the increased crop productivity in soils amended with biochar is likely to increase production of roots and above-ground residues, thus contributing with more biogenic carbon storage in the ground. Moreover, biochar can have beneficial impacts on other GHG emissions from soils, especially by reducing $\mathrm{N}_{2} \mathrm{O}$ emissions (Cayuela et al. 2014). These indirect effects have not been included in the assessment due to lack of data from the three experimental areas. However, they would all reduce the climate impact of the Biochar system further, in absolute terms and compared with the reference and charcoal systems.

The effects of introducing biochar-producing gasifier cookstoves on use of agricultural residues and firewood are important for reducing the total climate impact of the system since carbon stocks in vegetation and soils are preserved or increased when fuel demand is reduced. In the climate impact assessment presented here, the direct effects of changes in fuel demand on carbon stocks in vegetation were included, but not potential long-term increase in soil $\mathrm{C}$ stock due to reduced biomass fuel use. Under other circumstances than those reported here, bioenergy produced during biochar production can substitute fossil fuels and thus provide climate change mitigation in another way. While published LCAs of biochar systems normally include the different mitigation pathways described above, current reviews of negative emission technologies do not always acknowledge such multiple system benefits (Fuss et al. 2018).

If organic resources are scarce and unsustainably harvested, it may be better to use char for energy than as a soil amendment and thus reduce demand for primary fuels. Even though the LCA showed that use of biochar as a soil amendment was still slightly better in this case (comparing Biochar with Charcoal in non-renewable in Fig. 4), there are other socio-economic factors to consider, such as costs and labour needed for accessing fuels and also indirect damage on ecosystems from biomass harvesting. 


\subsection{Other potential benefits}

Many households have access to woodfuels on farm, primarily prunings that come from fruit trees and bushes, coffee plants or trees specifically grown for fuel and construction wood. For many households, this homegrown fuel does not cover their full fuel needs. During parts of the year, fuel must be sourced externally, such as collecting from a nearby forest or buying fuelwood. With more efficient cookstoves, the period when the households run short of firewood sourced from farms could be shortened. In this way, households can save costs in terms of labour or cash by more efficient use of fuels, and the pressure on the ecosystems from wood collection can be reduced, which can provide diverse environmental benefits on biodiversity and other ecosystem services. Higher yields in agriculture may also provide opportunities for more tree cultivation on the farm since less land is needed to sustain food supply (Pretty et al. 2011).

Indoor air pollution is a major source of respiratory and cardiovascular disease, globally estimated to cause 3.8 million deaths annually (WHO 2018). With reduced emissions from the use of gasifier cookstoves, an improvement in the health of women and children can be expected, though the scientific evidence for health improvements is still inconclusive (Quansah et al. 2017). Moreover, the reduced need for fuel due to efficient combustion reduced the need for women to carry heavy loads of fuelwood.

\subsection{Limitations and requirements for successful implementation of biochar on smallholder farms}

Maize has been the main crop in most of our biochar field trials and has shown good response to biochar addition. Maize is highly relevant since it is a staple crop in Kenya. However, with a focus on smallholder farmers with limited biomass resources and biochar production in combination with cooking, the biochar production capacity will be limited. Theoretically, the maximum biochar production during cooking is in the range of $1 \mathrm{~kg}$ biochar per household per day, but much less has been collected by the farmers involved in the trials. With $300 \mathrm{~kg}$ of biochar per farm per year, 0.1 ha could be supplied at a rate of $3 \mathrm{Mg} \mathrm{ha}^{-1}$, which would cover 1 ha in 10 years. This rate of production is small but still relevant, considering that average farm size in Kenya is below 2.5 ha, in many places much smaller and continually decreasing (Lowder et al. 2016). By placing the biochar in the root zone, as was done in our participatory trials with farmers, the biochar effect likely became stronger compared with even broadcasting over the whole plot (Cornelissen et al. 2013). Due to the low biochar production capacity, it is relevant to also search for other crops than maize that could benefit from biochar application. These should preferably be high-value crops with good response to biochar addition. Our field trial with kale was inconclusive since there was a drought during the time of our trials, which affected results and farmer participation, but there was a positive response to biochar in two thirds of the test fields. Soya bean, which has been included in the crop rotation in the longterm field experiments, is another crop that can be of interest for biochar application. There are further opportunities with combinations of biochar and organic amendments such as manure and compost (Agegnehu et al. 2016), which were not investigated in this project.

The cookstoves tested provide multiple benefits in terms of biochar production, fuel use efficiency and reduced pollution. Even though these benefits were appreciated by users, the adoption of the cookstove is not at all self-evident. Firstly, there were labour-demanding tasks in fuel preparation and refilling. Secondly, a simple switch from one stove to another cannot be 
expected since households use a variety of fuels and stoves for different cooking purposes, depending on a variety of factors including type of meal and availability of labour and fuel. Opportunities for cookstove design modifications through co-learning to understand the cooking culture are currently under investigation, and it would also be of interest to compare other biochar-producing cookstoves as well.

Moreover, local socio-cultural and economic conditions play a strong role for new technologies to be adopted and implemented at larger scale, as has been shown in studies coming from a variety of fields (Kedia and Bhagat 1988; Reddy and Zhao 1990; Fu et al. 2011). In the specific case of rural Africa where household power structures are still dominated by patriarchal systems, often with a rigid gender labour division, there is a need to pay attention to the type of activities impacted by the new technology. Our preliminary observations confirm that the degree of adoption and use of the cookstoves offered in our project is strongly related to several socio-cultural and economic variables. First, in those sites where the agricultural production is more diversified and commercialized (e.g. Embu), the adoption rate was lower than in those sites where agriculture is less diversified and still dominated by subsistence production (such as in Siaya). Second, the dietary preferences as well as the size of the household influence the level of adoption and use of the stoves. Stoves tend to be used more for meals that require less time than for those requiring longer time. The quantity of food to be cooked seems also to play a role. Due to the size of the stove, households with less members use them more than those with more members do. Third, despite the fact that cooking is the responsibility of women in all sites, the male participation in this project differs strongly from one site to the other. This suggests that it is important to include men even if the project targets women for transformative change as they too need to understand that improving cooking and agricultural systems benefits all household members and the community. However, these are preliminary results, and we are continuing with several studies to reach conclusions that are more definite.

\subsection{Further opportunities for biochar in an African context}

Present production methods and established markets for wood-derived charcoal are drivers for forest degradation in many parts of Africa (Chidumayoa and Gumbob 2013). Thus, a stimulation of the demand for biochar without introducing new efficient methods for its production would probably not be sustainable. Consequently, any efforts to increase use of biochar for soil fertility enhancement must be combined with promotion of methods to sustainably supply feedstocks and efficient conversion technologies for biochar production.

One way to increase biochar production capacity is to use waste biomass, which is available in many places where agricultural products are processed, such as rice husks, coffee husks or sawdust. Also on-farm non-traditional biomass sources, such as maize cobs or coconut shells are potential feedstocks. However, there may be competing uses for these resources such as animal feed, mulching, manure or fuel, which have to be assessed in each case to understand trade-offs. Technical development is ongoing for larger scale systems that combine biochar production with energy utilization, as these are likely to provide resource-efficient solutions for bioenergy as well as biochar (Nur and Syahputra 2018; Arnulfi and Fabris 2017).

For biochar introduction to be successful, there is need for development of recommendations and decision support systems that relate production and use of biochar to benefits to soil functions and crop productivity. There is also a need for development of conversion technologies and for matching biomass, conversion technology and applications. Through 
transdisciplinary collaborations, farmers/grassroots researchers, researchers from the global North and South, policy makers and industry can co-create knowledge on sustainable biochar systems. Transdisciplinary approaches goes beyond blending disciplines and have been proven effective in co-creation of knowledge and co-implementation of innovations with stakeholders to solve real societal problems (Vilsmaier et al. 2017).

\subsection{Recommendations}

We provide strong evidence for promoting the production of biochar produced in gasifier cookstoves and its subsequent use as a soil amendment in rural sub-Saharan Africa, as it provides negative greenhouse gas emissions, increases agricultural productivity and reduces fuel scarcity. However, biochar use should only be promoted in combination with cookstoves or other clean production technology that makes use of excess heat. Moreover, the introduction of biochar technology is only advisory if renewable biomass is used, or if the use of unsustainable biomass resources is reduced. If these requirements are not met, there is a risk that the climate benefit of adding biochar to soil is nullified by emissions in earlier steps of the biochar life cycle.

The use of biochar in tropical soils has potential as a method for climate change adaptation through increased resistance to moderate droughts. This topic requires further research.

Biochar that is produced in cookstoves and used locally is a negative emission technology with the potential to bring benefits for poverty alleviation through increased food and energy security. However, for this potential to be realized, it is important to reach also the households with lower capacity for uptake of new technology and those with the least access to land and fuel. This requires careful planning and implementation of policy and projects supporting uptake of this technology.

\section{Conclusions and outlook}

Biochar production in gasifier cookstoves and use of biochar in agriculture have the potential to improve conditions for smallholder farmers in Africa while contributing with net negative greenhouse gas emissions. In experiments involving 150 farmers in rural Kenya, biochar produced in gasifier cookstoves from local biomass resulted in considerably increased yields in maize cultivation, when applied at rates that are viable at current production capacity and land sizes of smallholder farms in Kenya. The cookstoves were appreciated for their fuel use efficiency and reduction of indoor air pollution, but the design tested did not fulfil all user expectations due to labour-demanding fuel preparation and refilling. Thus, the suitability of this cookstove design for long-term adoption is not established, and further participatory research and development of cookstove designs is needed.

The climate impacts in a life cycle perspective were considerably lower for the system with cookstove production of biochar and use of biochar in agriculture than for current cooking practices. This biochar system achieved net negative greenhouse gas emissions in a 100-year perspective at the current rate of deforestation in Kenya. Biochar production and use are thus promising technologies for climate change mitigation and net negative emissions. When considering biochar in climate policy contexts, the potential additional benefits for sustainable development should be highlighted. Biochar may also have a role in adaptation to climate change, by increasing crop resilience to moderate drought. This should be investigated further. 
Biochar introduction can provide multiple benefits beyond carbon sequestration, such as improved crop productivity, reduced emissions from biomass combustion, improved fuel efficiency and thus reduced pressure on fuel resources. These biophysical benefits will have beneficial implications on livelihoods, including gender equity. Key requirements for this to be fulfilled are sustainable sourcing of biomass and production of biochar using biomass conversion technologies that are more efficient and produce fewer emissions than current systems for biomass energy. Successful implementation will require changes in cooking systems including fuel supply, as well as farming systems, which, in turn, requires an understanding of local socio-cultural conditions, including power relations and gender aspects.

Funding information Open access funding provided by Royal Institute of Technology. The research has been funded by The Swedish Research Council, grant no. 2015-03180 and The Swedish Research Council for Environment, Agricultural Sciences and Spatial Planning, grant nos. 924-2015-1112 and 942-2015-1648.

Open Access This article is licensed under a Creative Commons Attribution 4.0 International License, which permits use, sharing, adaptation, distribution and reproduction in any medium or format, as long as you give appropriate credit to the original author(s) and the source, provide a link to the Creative Commons licence, and indicate if changes were made. The images or other third party material in this article are included in the article's Creative Commons licence, unless indicated otherwise in a credit line to the material. If material is not included in the article's Creative Commons licence and your intended use is not permitted by statutory regulation or exceeds the permitted use, you will need to obtain permission directly from the copyright holder. To view a copy of this licence, visit http://creativecommons.org/licenses/by/4.0/.

\section{References}

Agegnehu G, Nelson PN, Bird MI (2016) Crop yield, plant nutrient uptake and soil physicochemical properties under organic soil amendments and nitrogen fertilization on Nitisols. Soil Tillage Res 160:1-13

Andersson JA, D'Souza S (2014) From adoption claims to understanding farmers and contexts: a literature review of conservation agriculture (CA) adoption among smallholder farmers in southern Africa. Agric Ecosyst Environ 187:116-132

Arnulfi GL, Fabris M (2017) A stand-alone syngas-fuelled small-size CHP GT. Proc ASME Turbo Expo 3

Bailis R, Ezzati M, Kammen DM (2003) Greenhouse gas implications of household energy technology in Kenya. Environ Sci Technol 37:2051-2059

Biederman LA, Harpole WS (2013) Biochar and its effects on plant productivity and nutrient cycling: a metaanalysis. GCB Bioenergy 5:202-214

Bonjour S, Adair-Rohani H, Wolf J, Bruce NG, Mehta S, Pruss-Ustun A, Lahiff M, Rehfuess EA, Mishra V, Smith KR (2013) Solid fuel use for household cooking: country and regional estimates for 1980-2010. Environ Health Perspect 121:784-790

Cayuela ML, van Zwieten L, Singh BP, Jeffery S, Roig A, Sanchez-Monedero MA (2014) Biochar's role in mitigating soil nitrous oxide emissions: a review and meta-analysis. Agric Ecosyst Environ 191:5-16

Chidumayoa EN, Gumbob DJ (2013) The environmental impacts of charcoal production in tropical ecosystems of the world: a synthesis. Energy Sust Dev 17:86-94

Cornelissen G, Martinsen V, Shitumbanuma V, Alling V, Breedveld G, Rutherford D, Sparrevik M, Hale S, Obia A, Mulder J (2013) Biochar Effect on Maize Yield and Soil Characteristics in Five Conservation Farming Sites in Zambia. Agron 3:256-274

Drigo R, Bailis R, Ghilardi A, Masera O (2015) WISDOM Kenya: Analysis of woodfuel supply demand and sustainability in Kenya Tier 2 Report GACC Yale-UNAM Project Geospatial Analysis and Modeling of Non-Renewable Biomass: WISDOM and beyond https://cleancookstoves.org/binarydata/RESOURCE/file/000/000/426-1.pdf. Accessed 30 Aug 2018

Fu X, Pietrobelli C, Soete L (2011) The role of foreign technology and indigenous innovation in the emerging economies: technological change and catching-up. World Dev 39:1204-1212

Fuglestvedt JS, Berntsen TK, Godal O, Sausen R, Shine KP, Skodvin T (2003) Metrics of climate change: assessing radiative forcing and emission indices. Clim Chang 58:267-331

Fuss et al (2018) Negative emissions - part 2: costs, potentials and side effects. Environ Res Lett 13:063002 
Gitau JK, Mutune J, Sundberg C, Mendum R, Njenga M (2019) Implications on livelihoods and the environment of uptake of gasifier cook stoves among Kenya's rural households. Appl Sci 9:1205

Glover D, Sumberg J, Andersson JA (2016) The adoption problem; or why we still understand so little about technological change in African agriculture. Outlook Agric 45:3-6

Grieshop AP, Marshall JD, Kandlikar M (2011) Health and climate benefits of cookstove replacement options. Energy Policy 39:7530-7542

Jeffery S, Abalos D, Prodana M, Bastos AC, Van Groenigen JW, Hungate BA, Verheijen F (2017) Biochar boosts tropical but not temperate crop yields. Environ Res Lett:12053001

Jetter J, Zhao Y, Smith KR, Khan B, Yelverton T, DeCarlo P, Hays MD (2012) Pollutant emissions and energy efficiency under controlled conditions for household biomass cookstoves and implications for metrics useful in setting international test standards. Environ Sci Technol 46(19):10827-10834

Kätterer T, Roobroeck D, Andrén O, Kimutai G, Karltun E, Kirchmann H, Nyberg G, Vanlauwe B, Röing de Nowina K (2019) Biochar addition persistently increased soil fertility and yields in maize-soybean rotations over 10 years in sub-humid regions of Kenya. Field Crop Res 235:18-26

Kedia BL, Bhagat RS (1988) Cultural constraints on transfer of technology across nations: implications for research in international and comparative management. AcadManag Rev 13:559-571

Le QB, Nkonya E, Mirzabaev A (2016) Biomass productivity-based mapping of global land degradation hotspots. In: Nkonya E, Mirzabaev A, von Braun J (eds) Economics of land degradation and improvement - a global assessment for sustainable development. Springer, pp 55-84

Leblois A, Damette O, Wolfersberger J (2017) What has driven deforestation in developing countries since the 2000s? Evidence from new remote-sensing data. World Dev 92:82-102

Lowder SK, Skoet J, Raney T (2016) The number, size and distribution of farms, smallholder farms and family farms worldwide. World Dev 87:16-29. https://doi.org/10.1016/jworlddev201510041

Minx JC, Lamb WF, Callaghan MW, Fuss S, Hilaire J, Creutzig F, Amann T, Beringer T, de Oliveira Garcia W, Hartmann J, Khanna T, Lenzi D, Luderer G, Nemet GF, Rogelj J, Smith P, Vicente Vicente JL, Wilcox J, del Mar Zamora Dominguez M (2018) Negative emissions - part 1: research landscape and synthesis. Environ Res Lett 13:063001

Njenga M, Iiyama M, Jamnadass R, Helander H, Larsson L, de Leeuw J, Neufeldt H, Roing de Nowina K, Sundberg C (2016) Gasifier as a cleaner cooking system in rural Kenya. J Clean Prod 121:208-217

Njenga M, Mahmoud Y, Mendum R, Iiyama M, Jamnadass R, Roing de Nowina K, Sundberg C (2017) Quality of charcoal produced using micro gasification and how the new cook stove works in rural Kenya. Environ Res Lett 12(9)

Nur TB, Syahputra AW (2018) Integrated biomass pyrolysis with organic Rankine cycle for power generation. IOP Conf Ser: Mater Sci Eng 308(1):012030

Pretty J, Toulmin C, Williams S (2011) Sustainable intensification in African agriculture. Int J Agric Sustain 9:524. https://doi.org/10.3763/ijas20100583

Quansah R, Semple S, Ochieng CA, Juvekar S, Ato Armah F, Luginaah I, Emina J (2017) Effectiveness of interventions to reduce household air pollution and/or improve health in homes using solid fuel in low-andmiddle income countries: a systematic review and meta-analysis. Environ Int 103:73-90

Reddy NM, Zhao L (1990) International technology transfer: a review. Res Policy 19(4):285-307

Smith K, Uma R, Kishore V, Lata KVN, Joshi V, Zhang J, Khalil MAK (2000a) Greenhouse gases from smallscale combustion devices in developing countries: phase IIa - household stoves in India report prepared for EPA EPA-600/R-00-052. Office of Research and Development US Environmental Protection Agency, Washington DC

Smith K, Uma R, Kishore V, Zhang J, Joshi V, Khalil M (2000b) Greenhouse implications of household stoves: an analysis for India. Annu Rev Energy Environ 25:741-763

Sparrevik M, Field JL, Martinsen V, Breedveld GD, Cornelissen G (2013) Life cycle assessment to evaluate the environmental impact of biochar implementation in conservation agriculture in Zambia. Environ Sci Technol 47:1206-1215

Stanistreet D, Puzzolo E, Bruce N, Pope D, Rehfuess E (2014) Factors influencing household uptake of improved solid fuel stoves in low- and middle-income countries: a qualitative systematic review. Int J Environ Res Public Health 11:8228-8250. https://doi.org/10.3390/ijerph110808228

Thomas E, Wickramasinghe K, Mendis S, Roberts N, Foster C (2015) Improved stove interventions to reduce household air pollution in low and middle income countries: a descriptive systematic review. BMC Public Health 15:650

Vilsmaier, U et al. (2017) ITD Conference 2017. Abstracts booklet. Leuphana University of Lüneburg, Swiss Academy of Arts and Sciences and td-net Network for Transdisciplinary (2017). https://www.leuphana. de/fileadmin/user_upload/Forschungseinrichtungen/ietsr/personen/vilsmaier_ulli/files/ITD17 booklet_26.9.17.pdf. Accessed 29 Aug 2018 
Whitman T, Nicholson C, Torres D, Lehmann J (2011) Climate change impact of biochar cook stoves in Western Kenyan farm households: system dynamics model analysis. Environ Sci Technol 45:3687-3694

WHO (2018) Household air pollution and health Fact sheet. World Health Organization http://wwww. hoint/news-room/fact-sheets/detail/household-air-pollution-and-health. Accessed 10 Aug 2018

Publisher's note Springer Nature remains neutral with regard to jurisdictional claims in published maps and institutional affiliations.

\section{Affiliations}

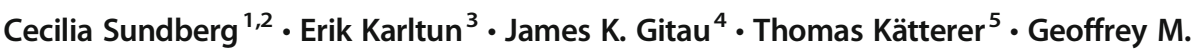 Kimutai $^{6}$ - Yahia Mahmoud ${ }^{7} \cdot$ Mary Njenga $^{4,8} \cdot$ Gert Nyberg $^{9} \cdot$ Kristina Roing de Nowina $^{3,10}$ - Dries Roobroeck ${ }^{6}$ - Petra Sieber ${ }^{2}$}

Cecilia Sundberg

cecilia.sundberg@abe.kth.se

1 Department of Sustainable Development, Environmental Science and Engineering (SEED), KTH Royal Institute of Technology, Stockholm, Sweden

2 Department of Energy and Technology, Swedish University of Agricultural Sciences, Uppsala, Sweden

3 Department of Soil and Environment, Swedish University of Agricultural Sciences, Uppsala, Sweden

4 Wangari Maathai Institute for Peace and Environmental Studies, University of Nairobi, Nairobi, Kenya

5 Department of Ecology, Swedish University of Agricultural Sciences, Uppsala, Sweden

6 IITA, Nairobi, Kenya

7 Department of Human Geography, Lund University, Lund, Sweden

8 World Agroforestry (ICRAF), Nairobi, Kenya

9 Department of Forest Ecology and Management, Swedish University of Agricultural Sciences, Umeå, Sweden

10 CGIAR System Organization, Montpellier, France 